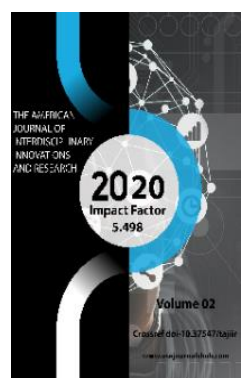

\title{
The Use Of Information And Communication Technologies In Mathematics Lessons
}

Toshpulatova Mamurakhon

PhD, Researcher, Tashkent State Pedagogical University, Uzbekistan

\section{ABSTRACT}

The process of informatization, which has embraced all aspects of the life of modern society today, has several priority areas, which, of course, should include the informatization of education. It is the fundamental principle of the global rationalization of human intellectual activity through the use of information and communication technologies (hereinafter ICT).

The ultimate goals of informatization of education are to provide a qualitatively new model for training future members of the information society, for whom active mastery of knowledge, flexible changes in their functions in work, the ability for human communication, creative thinking and planetary consciousness will become a vital necessity. Such a profound influence on learning goals is based on the potential of the computer as a means of cognitive and research activities, a means of providing a personality-oriented approach to learning, contributing to the development of individual abilities of students in both the humanities and the exact sciences.

\section{KEYWORDS}

Education, communication, individualization and differentiation, mathematics lessons, information and communication technologies.

\section{INTRODUCTION}

Modern society is undergoing significant changes associated with the rethinking of a number of scientific, political and social provisions. This happens in all spheres of human life, affects all social institutions, including the education system. In our country, whole groups of the population change their value orientations due to the avalanche-like 
growth of information. The rapid development of telecommunications and information technologies, the formation of the world information space imposes new requirements on modern society and its most important institution - the education system.

One of the priority directions of informatization of society is the process of informatization of education, which involves the widespread use of information technologies of education.

The middle of the gos of the last century to the present day, is characterized by the mass and availability of personal computers in Russia, the widespread use of telecommunications, which makes it possible to introduce the developed information technologies of education into the educational process, improving and modernizing it, improving the quality of knowledge, increasing the motivation for learning. making the most of the principle of individualization of training. Information technologies of teaching are a necessary tool at this stage of informatization of education.

Information technologies not only facilitate access to information and open up opportunities for variability of educational activities, their individualization and differentiation, but also allow to organize the interaction of all subjects of learning in a new way, to build an educational system in which the student would be an active and equal participant in educational activities.

The formation of new information technologies within the framework of subject lessons stimulates the need to create new software and methodological complexes aimed at a qualitative increase in the effectiveness of the lesson. Therefore, for the successful and purposeful use of information technology tools in the educational process, teachers must know the general description of the principles of functioning and the didactic capabilities of software applications, and then, based on their experience and recommendations, "embed" them into the educational process.

The study of mathematics is currently associated with a number of features, if not difficulties in the development of school education in our country. As noted in a number of articles, we even have to speak of a crisis in mathematics education. The reasons for it are as follows:

- In changing priorities in society and in science - at present, against the background of a sharp decline in interest in science as a whole, there is an increase in the priority of the humanities;

- In reducing the number of mathematics lessons at school;

- The isolation of the content of mathematics education from life (especially in mass schools);

- In small impact on the feelings and emotions of students.

I will allow myself to quote the statements of scientists from different times without detailed comments.

The purpose of knowledge is not memorizing a huge factual material in the smallest detail, but the ability to easily and quickly navigate this area. (A.N. Terenin)

It is not so important what is taught in school, but it is important how it is taught ... The 
function of a school is not to provide special experience, but to develop consistent methodological thinking. (M. Planck)

If a student does not experience the joy of searching and discoveries, does not feel the living process of the formation of ideas, then he rarely manages to achieve a clear understanding of all the circumstances that made it possible to choose this, and not some other path. (A. Einstein)

Gathering together the main provisions noted in these remarkably deep and modern in meaning statements, we can highlight the most important thing:

- The role of mathematics as an academic subject is extremely great in terms of shaping the world outlook and creative thinking of students not only in the field of natural science, but also in the most general sense;

- Knowledge, the solid foundations of which are formed when studying mathematics at school, should be as close as possible to real life and everyday practice:

- The study of mathematics should be carried out in such a way that students see science in constant historical development and, wanting to study it, feel satisfaction and joy from the process of learning.

The changes taking place today in modern society largely determine the characteristics and the need for changes in the activities of the teacher. In modern conditions, in educational activities, it is important to focus on the development of the cognitive independence of students, the formation of research skills, the individualization of the goals of education. It is impossible to solve this problem with the old methods. Years of teaching allowed me to see the contradictions in mass practice:

- Between the individual's desire for creativity, originality, self-expression and the obligatory unified plan and regime of a general education school;

- Between the reproductive, scholastic perception of mathematical material by individual students and the need for creative transformation of their mathematical activity;

- Between the increasing complexity and richness of the school curriculum, the constantly increasing level of requirements and the student's ability to master the entire volume of information offered to him.

These contradictions prompted me to work aimed at improving the quality of students' knowledge, developing their creative abilities through new information technologies.

\section{METHOD}

Today the question remains: "How can we most effectively use the potential of modern information and communication technologies in teaching schoolchildren, including teaching mathematics?" Therefore, the methodological problem that I have been working on lately is "The use of information and communication technologies in mathematics lessons as a means of increasing motivation for learning".

The task of the school is not only to communicate a certain amount of knowledge to students, but also to develop their cognitive interests, creative attitude to work, striving for independent "acquisition" and enrichment of 
knowledge and skills, and their application in their practical activities. The main work of our children is teaching, and therefore it is very important to teach them how to learn intelligently. It is generally recognized that mathematics is the most laborious academic subject that requires constant, painstaking and significant independent work from students, moreover, very specific and diverse. Therefore, one of the main tasks of a mathematics teacher is the formation and development of skills in studying mathematics, elements of the culture of learning and thinking. To do this, it is necessary to work out in detail the content aspect of training and select from the whole variety of methods, forms, technologies such that will lead students to master the conceptual components of the training program, will develop the cognitive abilities of students, their activity in educational activities, and will also ensure the formation and development of communicative competencies students. The increase in mental load in mathematics lessons makes you think about how to maintain students' interest in the subject under study, their activity throughout the lesson. In order to maintain interest in the subject and make the educational process of high quality, I actively use information technologies in my lessons. Active work with a computer forms in students a higher level of self-educational skills and abilities - analysis and structuring of the information received. At the same time, it should be noted that new teaching aids make it possible to organically combine information and communication, personality-oriented technologies with methods of creative and search activity. Today, the introduction of computer technology into the educational process is an integral part of school education. It is generally recognized that the use of computer technologies in education is inevitable, since the effectiveness of training and the quality of the knowledge and skills that are being formed are significantly increased.

\section{Goals and objectives of using ICT}

The purposes of using a computer in mathematics lessons are as follows: development of interdisciplinary connections between mathematics and computer science; the formation of computer literacy; development of students' independent work in the classroom; implementation of an individual, personality-oriented approach.

My tasks as a math teacher are as follows:

- Provide fundamental mathematical training for children;

- To form informational and methodological culture, creative style of students' activity;

- Prepare students to use information technology and other information structures.

The use of ICT in mathematics lessons enables the teacher to reduce the time spent on studying the material due to the clarity and speed of the work, to check the knowledge of students in an interactive mode, which increases the effectiveness of learning, helps to realize the full potential of the individual cognitive, moral, creative, communicative and aesthetic, contributes to the development of intelligence, information culture of students.

The use of ICT in the educational process involves improving the quality of education, that is, solving one of the pressing problems for modern society. 
The process of organizing education for schoolchildren using ICT allows:

- To make this process interesting, on the one hand, due to the novelty and unusualness of this form of work for students, and on the other hand, to make it exciting and bright, diverse in form by using the multimedia capabilities of modern computers;

- Effectively solve the problem of visualization of teaching, expand the possibilities of visualization of educational material, making it more understandable and accessible for students to freely search for the educational material necessary for schoolchildren in remote databases through the use of telecommunications, which will further contribute to the formation of students' need for search actions;

- Individualize the learning process due to the presence of multi-level tasks, due to immersion and assimilation of educational material at an individual pace, independently, using convenient ways of perceiving information, which causes positive emotions in students and forms positive learning motives;

- To liberate students when answering questions, because the computer allows you to record the results (including without scoring), correctly responds to errors; independently analyze and correct mistakes made, correct their activities due to the presence of feedback, as a result of which self-control skills are improved;

- Carry out independent educational and research activities (modeling, project method, development of presentations, publications, etc.), thereby developing creative activity among schoolchildren.

The modern information society sets before all types of educational institutions, and above all before the school, the task of preparing graduates who are capable of:

- Flexibly adapt to changing life situations,

- Independently think critically;

- Competently work with information;

- Be sociable, contact in various social groups; work independently on the development of their own morality, intellect, cultural level.

The use of information technologies in teaching is based on data from human physiology: $1 / 4$ of the material heard, $1 / 3$ of what is seen, $1 / 2$ of what is seen and heard, $3 / 4$ of the material, if the student actively participates in the process, remains in the memory of a person.

In order to intensify learning, along with the classical forms of teaching at school and in the independent work of students, which were previously used in teaching mathematics, the software of educational disciplines is increasingly used: textbook programs, training programs, dictionaries, reference books, encyclopedias, video lessons, libraries of electronic visual aids, thematic computer games.

The capabilities of a computer, when using additional technologies adapted to it: software products, the Internet, network and demonstration equipment, constitute the material base of information and communication technologies. 
Information technology, in my opinion, can be used at various stages of a mathematics lesson:

- Self-study with the absence or denial of the teacher's activities;

- Self-study with the help of a teacherconsultant;

- Partial replacement (fragmentary, selective use of additional material);

- The use of training (training) programs;

- Use of diagnostic and control materials;

- Completing home independent and creative tasks;

- Use of a computer for calculations, graphing;

- Using programs that simulate experiments and laboratory work;

- Use of game and entertaining programs;

- Use of information and reference programs.

Since the visual-figurative components of thinking play an extremely important role in a person's life, their use in the study of material using ICT increases the effectiveness of learning:

- Graphics and animation help students understand complex logical mathematical constructions;

- The opportunities provided to students to manipulate (explore) various objects on the display screen, change their speed of movement, size, color, etc., allow children to assimilate educational material with the fullest use of the sense organ and communication links of the brain.

The computer can be used at all stages of the learning process: when explaining new material, consolidating, repeating, monitoring, while for the student it performs various functions: a teacher, a working tool, a learning object, a collaborating team.

The computer allows you to enhance the motivation of learning through an active dialogue between the student and the computer, the variety and colorfulness of information (text + sound + video + color), by orienting the teaching towards success (it allows you to complete the solution of any problem, relying on the necessary help), using the game background of human communication with machine and, which is important, endurance, calmness and "friendliness" of the machine in relation to the student.

In addition to the above, it is of great importance that in the process of work of a student and a teacher using computer technology, the student, firstly, gradually enters the real world of adults, the production activity of a modern person.

Secondly, the widespread introduction of ICT into the life of a modern person poses a dilemma for teachers: either you keep up with the times, teach children in a modern way, using modern teaching technologies, or you lag behind and leave the profession.

When choosing the conditions for using ICT, I take into account:

- Availability of programs corresponding to the studied topic;

- The number of computerized workplaces;

- The readiness of students to work using a computer;

- The student's ability to use computer technology outside the classroom. 
Remembering the words of K. F. Gauss that "mathematics is a science for the eyes, not for the ears", I believe that mathematics is one of those subjects in which the use of ICT can intensify all types of educational activities: learning new material, preparation and verification of homework, independent work, test and control work, extracurricular work, creative work. Through the use of ICT, many methodological goals can be realized more effectively.

Information technology, according to G.K. Selevko can be implemented in three versions:

- As "penetrating" (using a computer in the study of certain topics, sections, for solving certain didactic problems);

- As the main one (the most significant in the used pedagogical technology);

- As a mono-technology (when all training and management of the educational process, including all types of diagnostics, control and monitoring, rely on the use of a computer).

Of course, the ideal option that every teacher strives for is monotechnical education, i.e. independent educational work of the child in an interactive learning environment using ready-made e-learning courses. The use of information technology must be considered in the indissoluble unity of all components of the educational process:

- Creation of lessons using IT;

- Creative project work of students;

- Distance learning, competitions;

- Library, Internet resources;

- Elective courses;
- Social and psychological monitoring of the formation of the student's personality;

- Creative interaction with teachers.

In the process of teaching mathematics, information technology can be used in various forms. The directions that I use can be represented in the form of the following main blocks:

- Multimedia scripts of lessons;

- Testing knowledge in the classroom;

- Extracurricular activities

Multimedia Lesson Scripts One of the benefits of using ICTs is the dramatic increase in time spent on independent work. Such a learning process allows you to develop thinking, to activate thought processes. Work will be creative if students' own intentions are manifested in it, new tasks are posed and independently solved with the help of newly acquired knowledge.

Using multimedia in lessons implements the following principles:

The principle of visibility. Allows you to use illustrative material, audio material, resources of rare illustrations in any lesson. The clarity of the material increases its assimilation by students, because all channels of students' perception are involved - visual, mechanical, auditory and emotional.

The principle of conformity to nature. The use of materials on the Internet is of interest to high school students. The use of multimedia presentations is advisable at any stage of the study of the topic and at any stage of the lesson. The presentation of educational 
material in the form of a multimedia presentation reduces the learning time, frees up the resources of children's health.

The principle of strength. The use of presentation lessons technically allows you to repeatedly return to the studied or studied material. The use of training programs allows you to recall the material of previous lessons in one lesson.

Scientific principle: the transformation of this principle in multimedia learning gets a more fundamental basis.

The principle of accessibility: this technology is integrated with the technology of differentiated teaching and allows you to simultaneously display multilevel tasks, control and test tasks, tasks of increased complexity on a monitor or screen.

The principle of consistency: the use of presentation lessons allows you to develop a system of lessons on one topic, as well as displaying the elements of previous lessons, to explain new things.

The principle of consistency: as in traditional lessons, the teaching material is memorized in greater volume and more firmly.

I practice conducting such lessons both when presenting new material and when repeating what has been passed.

Among the most basic advantages of the formation of material on an electronic medium, in my opinion, the opinion is the heterogeneity of the educational material (text, illustrations, animation), interactivity, instant search. All this information wealth, which opens up great prospects for a teacher, is, of course, impossible on paper. An electronic textbook has a number of undoubtedly positive properties that distinguish it favorably from traditional textbooks - the text of the textbook is accompanied by a large number of slides and video fragments that enhance the emotional and personal perception of the studied material by students; the use of such a textbook allows you to do much more in the lesson than using traditional means, to increase interest in the subject of mathematics. In my lessons I use disks of educational and methodological support in mathematics. However, not all discs available in the school media library, educational programs do not always correspond to the studied material, do not take into account the characteristics of the class, the content of the program. Therefore, I do not use them in full, but specific topics or tasks.

By their functional purpose, computer programs can be conditionally divided into four main types:

- Informational and illustrative (replaces conventional visual aids and traditional audio-visual teaching aids);

- Developmental programs (focused on the development of memory, attention, logic, spatial thinking of students);

- Training programs (imply the research work of students at the computer or training programs for obtaining certain skills);

- Control programs (most often programs for testing the level of learning of students. Such programs involve an individual survey of each student). 


\section{CONCLUSION}

A lesson is a social order of society in the education system, which is determined by the socio-psychological needs of society, the level of its development, moral and moral values of this society. Unfortunately, the process of modernization in the education system is difficult. This is due to the fact that teachers aim their students only at obtaining solid theoretical knowledge, some of which, in my opinion, will not receive practical application in future life.

It is no secret that the established practice of teaching mathematics is characterized by the traditional study of mathematical formulas, the abstractness of mathematical concepts, which are usually memorized mechanically.

In my opinion, in mathematics lessons, the stated problem can to some extent be solved by using computer technologies, which, firstly, are based on a strict algorithm of student actions. After all, not every student, having learned the rules, can use them. The use of algorithms, charts, tables, that is, orienting charts, streamlines the learning process.

Secondly, in connection with the acute problem of saving time in the course of the educational process, the modern school is also faced with the task of finding the means and teaching methods that will maximize the saving of time in the lesson. In my opinion, the use of a computer in the classroom is one of such means.

Thirdly, I believe that teaching using information and communication technologies is also level differentiation, because under the conditions of this technology, the student has the right to choose the content of his education, the level of assimilation. At the same time, the teacher's activity should provide an opportunity for each student to master knowledge at a mandatory or higher level (at the student's choice).

In accordance with the goals set, ICT should help the student to acquire better knowledge, which is necessary for the successful passing of the Unified State Exam.

In addition, the following can be distinguished as the expected results of the project:

- Formation of key competencies of students in the learning process and in extracurricular activities;

- Increasing the motivation for learning of students;

- Mastering computer literacy by students, increasing the level of computer literacy among teachers;

- Organization of independent and research activities of students;

- Creation of our own bank of educational and teaching materials, ready for use in the educational process.

- Development of spatial thinking, cognitive abilities of students;

- Aesthetic appeal of the lessons.

The experience I have accumulated, partially reflected in this work, shows that the use of information technologies in the classroom and in extracurricular activities expands the creative possibilities of both the teacher and students, increases interest in the subject, stimulates the development of quite serious topics in computer science by students, which, as a result, leads to an intensification of the learning process. 
From the above, it follows that knowledge is assimilated by a student through his own activity, organized and controlled so that the student has before him real guidelines that allow him to perform all actions correctly and at the same time control himself.

The last decade of the outgoing century has put the school in a situation of the need to introduce significant changes in the system of education and upbringing of students. These changes should be ensured by the school reform, which is dictated by the modernization of education, computerization of schools. I think that the use of information and communication technologies in mathematics lessons to some extent contribute to solving this problem.

\section{REFERENCES}

1. Agzamxodjaeva S. ljtimoiy ideal va ma'naviy hayot. - Toshkent: Falsafa va huquq, 2007.

2. Musaev F. Demokratik davlat kurishning falsafiy-huquqiy asoslari. - Toshkent: O'zbekiston, 2007.

3. O'zbekistonda progressiv ijtimoiy-falsafiy fikrlar tarixiga doir materiallar. - Toshkent: Fan, 1959.

4. Selevko G.K. Sovremennie pedagogicheskiye texnologii: Uchebnoye posobiye. M.: Narodnoye obrazovaniye, 1998. $256 \mathrm{~s}$.

5. Informatsionnie texnologii na urokax matematiki. Starseva Nadejda Alekseyevna, s.n.s. Instituta elektronnix programmno-metodicheskix sredstv obucheniya RAO. 